'But Not Both: The Exclusive Disjunction in Qualitative Comparative Analysis (QCA)'

\author{
Ursula Hackett \\ Department of Politics and International Relations, University of Oxford \\ ursula.hackett@politics.ox.ac.uk
}

\begin{abstract}
This paper has been accepted for publication and will appear in a revised form, subsequent to editorial input by Springer, in Quality and Quantity, International Journal of Methodology. Copyright: Springer (2013)
\end{abstract}

\begin{abstract}
The application of Boolean logic using Qualitative Comparative Analysis (QCA) is becoming more frequent in political science but is still in its relative infancy. Boolean 'AND' and 'OR' are used to express and simplify combinations of necessary and sufficient conditions. This paper draws out a distinction overlooked by the QCA literature: the difference between inclusive- and exclusive-or (OR and XOR). It demonstrates that many scholars who have used the Boolean OR in fact mean XOR, discusses the implications of this confusion and explains the applications of XOR to QCA. Although XOR can be expressed in terms of OR and AND, explicit use of XOR has several advantages: it mirrors natural language closely, extends our understanding of equifinality and deals with mutually exclusive clusters of sufficiency conditions. XOR deserves explicit treatment within QCA because it emphasizes precisely the values that make QCA attractive to political scientists: contextualization, confounding variables, and multiple and conjunctural causation.
\end{abstract}


The primary function of the phrase 'either...or' is 'to emphasize the indifference of the two (or more) things...but a secondary function is to emphasize the mutual exclusiveness', that is, either of the two, but not both (Simpson 2004). The word 'or' has two meanings:

Inclusive 'or' describes the relation 'A or B or both', and can also be written 'A and/or B'. Exclusive 'or' describes the relation 'A or B, but not both'.

Qualitative Comparative Analysis (QCA) currently deploys only Boolean 'AND' and the inclusive disjunction 'OR' to express and simplify combinations of necessary and sufficient conditions. But in this paper I argue that QCA should also use the exclusive disjunction 'XOR', because the XOR mirrors natural language closely, deals with mutually exclusive clusters of sufficiency conditions, and extends our understanding of equifinality - the notion that different causal paths can lead to the same outcome. The exclusive disjunction deserves explicit treatment because it emphasizes precisely the values that make QCA attractive to political scientists: contextualization and complexity, confounding variables, and multiple, conjunctural causation (Schneider and Wagemann 2006).

The exclusive, not the inclusive, disjunction should be used wherever there is logical or practical incompatibility between two or more competing paths to an outcome - they cannot both be taken at the same time. Regrettably, the distinction between inclusive and exclusive 'or' has been treated with casual disregard across the discipline of political science, not just those parts of it that use the QCA method. 'A or B' is often implicitly taken to mean: 'A or B (but not both)' rather than 'A or B (or both)', with resultant confusion. The exclusive disjunction is already widely discussed by linguists, philosophers and logicians, and used extensively in the electrical engineering literature (Hurford 1974; Akers 1959; Jennings 1994; Fleisher, Tavel, and Yeager 1983). It is also commonly,

\footnotetext{
${ }^{1}$ In H.P. Grice's terms, the word 'or' has a conversational implicature, something that can be worked out from how something was said, rather than simply what was said. Usually there are contextual clues that indicate whether the 'or' used is exclusive or inclusive. For example, the 'or' in 'you may have tea or coffee' sounds inclusive when stated in a neutral tone, but exclusive if the 'or' is given heavy emphasis. See Grice's 1989 work Studies in the Way of Words for discussion of both conversational and conventional implicature.
} 
if implicitly, deployed both in ordinary language and social science (Felix 1994). Table 1 shows a selection of published papers that use exclusive disjunctions:

[TABLE 1 ABOUT HERE]

Since exclusive disjunctions are common in the formulation of social science theories and hypotheses, users of QCA should pay attention to the distinction between OR and XOR. Some scholars have done so. For instance, in their discussion of QCA Wagemann and Schneider draw attention to the inclusivity of the Boolean OR by stating that their solution formulas are not mutually exclusive (Wagemann and Schneider 2010a, 381). The titles of some social science articles also give explicit notice that the 'or' used is inclusive rather than exclusive, whether they use QCA or not, as shown in Table 2:

[TABLE 2 ABOUT HERE]

Not all users of QCA acknowledge the inclusivity of the OR and the distinction between OR and XOR. But they ought to, because political scientists often deal with alternative paths that are mutually exclusive. Politics and indeed social life more generally, is about allocating scarce resources and deciding between alternatives. Public policies are 'choices between incompatible alternatives' (Hodder-Williams 1996, 286). Social scientists frequently investigate intermediate outcomes between competing public policies, electoral systems or regime types ('why didn't we get as far as here? But then, why did we get anywhere at all?'), where there are scarce resources and numerous informational constraints on policymakers. The inclusive disjunction cannot deal with these central features of social science research, because it really means 'and/or'. It fails to capture the hard edges of political decision-making where it is not possible to pursue both courses together. The exclusive disjunction captures this mutual exclusivity of political alternatives. 
The three main uses for the exclusive 'or' in social scientific research are where two courses are logically incompatible, or where one or other of the conditions can produce the outcome but it is practically impossible to have both at the same time- because they would violate some commitment or constraint, or because they would together overshoot the desired outcome. To illustrate, consider the following examples based on published social scientific research:

(1) Practical incompatibility (violation of a constraint): Economic stabilization (S) can be achieved by the imposition of several fiscal rules, for example tight debt and budget balance rules (D) or tight expenditure and revenue rules (X), but the combination of all of these fiscal rules (D and X) can hinder the country's ability to respond to economic shocks, undermining transparency and generating incentives for creative accounting (Milesi-Ferretti 2004; Schaechter et al. 2012). Since the government does not wish to experience these negative outcomes, it will choose either D or X, but not both.

(2) Practical incompatibility (overkill): Universities hit the government's 'tolerance band' for admissions ( $\mathrm{T})$ by attracting students in several ways, for example performing well (P) or an aggressive web-based recruitment drive (W); if the university has neither $\mathrm{P}$ nor $\mathrm{W}$, it will 'undershoot' the admissions band ( $\mathrm{t})^{2}$ and lose funding; if it has both $\mathrm{P}$ and $\mathrm{W}$, it is in danger of 'overshooting' the admissions band (t) and incurring sanctions. To hit the correct intermediate outcome $(\mathrm{T})$ it must strike a balance between the two conditions: $\mathrm{P}$ or W, but not both (Ferris 1992; Whitehead 2012).

(3) Logical incompatibility: 'British Politicians: To Rehabilitate or Not?' (Hodder-Williams 1996) public enjoyment of its sleazy politicians (E) can be achieved by either rehabilitation and changes to

\footnotetext{
${ }^{2}$ In Boolean logic, upper-case letters represent the presence of a condition and lower-case letters represent its absence.
} 
politicians' relationship with the media $(\mathrm{Rm})$ (because the public would hold the politicians in higher esteem) or no rehabilitation and retention of the status quo relationship between politicians and the media (rM) (because it would enjoy reading about its representatives' peccadillos in newspapers), but it is impossible to do both ( $\mathrm{Rm}$ and $\mathrm{rM}$ ) because the two courses are logically incompatible: conditions and their negation.

None of the published research on which these three examples are based uses QCA techniques. But this fact does not detract from the three lessons to which it gives rise, which are applicable to all areas of social science and not just QCA methodology. First, the exclusive disjunction is common. Secondly, its exclusivity is usually left implicit. Thirdly, exclusivity is central to political life, where 'hard choices must be made; some views must be ignored; bargains must be struck; priorities must be decided upon' (Hodder-Williams 1996, 287). Social scientists should pay attention to exclusivity issues because exclusivity is a defining characteristic of the phenomena they study. This paper examines the three main uses for the exclusive disjunction: scenarios where prior commitments on the causal configuration side, intermediate outcome solutions that can easily be overshot, and logically incompatible configurations, make use of the standard inclusive disjunction inappropriate because the causal conditions are mutually incompatible. A glossary of technical terms is available in the appendix.

By mimicking the exclusive disjunctions of natural language closely while adding an additional logical tool to QCA, explicit use of the XOR helps fulfil the goals to which Taagepera urges social science to attend: the interconnected examination of 'what is' and 'how things should be on logical grounds' (Taagepera 2008), that is, both description and explanation. XOR describes a common way people speak and thereby improves the precision and scope of the expression of explanatory conditions in QCA. The Boolean OR allows the inter-substitution, mixing, matching and addition of the any of the various causal paths but is not appropriate for every QCA analysis. The 
acceptance of multiple conjunctural causation by QCA does not mean that 'anything goes' when creating a 'causal recipe'. This paper shows that there are situations in which the XOR is more suitable than the OR.

It is possible that with limited diversity some disjunctions may seem exclusive rather than inclusive merely because there happen to be no empirical instances of the two conditions occurring together. With two causal conditions $\mathrm{A}$ and $\mathrm{B}$ and an outcome condition $\mathrm{Y}$, a researcher might observe instances of $\mathrm{Ab}, \mathrm{aB}$, and $\mathrm{ab}$, with the former two paths associated with $\mathrm{Y}$ and the third with $\mathrm{y}$, and suggest that $\mathrm{A} \oplus \mathrm{B} \rightarrow \mathrm{Y}$. Limited diversity can obstruct realistic theory-building and obscure true causal relationships in all social scientific investigations, not just those that use QCA. However, the problems of limited diversity can be addressed by proper formalization and close attention to the distinction between OR and XOR. An exclusive disjunction does not simply describe a coincidence that A and B are simply never observed together - but rather, an assertion that A and B cannot occur together - either because of an external (practical) constraint, or because of an internal (logical or practical) one. The use of the XOR invites the researcher to consider carefully the reasons why one or other condition, but not both, produces the outcome.

The paper proceeds as follows: Section one describes the characteristics of the Boolean XOR and gives an overview of how Boolean logic is used in QCA to express relationships between causal conditions. Section two gives four examples of confusion regarding the Boolean OR in published social science research, and demonstrates that the XOR should have been used instead. Section three covers logical incompatibility between causal recipes and section 4 deals with practical incompatibility: the situations in which XOR can be applied in QCA fruitfully. Section 5 extends the Boolean XOR to fuzzy sets and explains how it can be applied in fuzzy set Qualitative Comparative Analysis (fsQCA). Section six concludes.

\section{Characteristics of XOR}


The truth table of the Boolean AND (Table 3) and OR (Table 4) can be contrasted with the Boolean XOR (Table 5) below. A and B in columns 1 and 2 represent two (crisp-set) causal conditions and show all logically possible, mutually exclusive and jointly exhaustive conglomerations of these two conditions. The third column displays the values created by the application of the Boolean operator to the two conditions.

\section{[TABLES 3, 4 AND 5 ABOUT HERE]}

Figures 1, 2 and 3 display the information in tables 3,4 and 5 pictorially:

[FIGURES 1, 2 AND 3 ABOUT HERE]

Table 3, the truth table for AND $(*)$, shows that the value of $A * B$ is 1 just in case both the values of $A$ and $B$ are 1 . Its value is 0 if either $A$ or $B$ or both are 0 . By contrast for OR (+), the value of $\mathrm{A}+\mathrm{B}$ is 1 wherever $\mathrm{A}$, or $\mathrm{B}$, or both, are 1 , and 0 only where both $\mathrm{A}$ and $\mathrm{B}$ are 0 , according to Table 4. Hence AND and OR represent opposite ends of a strictness spectrum: a case's set membership of $\mathrm{A}^{*} \mathrm{~B}$ is the minimum value of the two conditions (because if even one of the conditions does not hold then the whole also fails to hold), whereas a case's set membership of A+B is the maximum value of the two conditions (because if either one of the conditions holds then the whole holds) (Ragin 2008). AND is strict while OR is loose.

To give a concrete example: amongst scholars studying European fiscal policy, some examine the effect of the political system on the behaviour of policymakers and others focus on disagreement between various decision-makers (Haan and Sturm 1994). Scholars of the first school argue that high debt accumulation by EU member states (D) occurs when there is political instability 
(I) or party polarization (P) because such political systems behave myopically, as shown in Proposition 4. The arrow $\rightarrow$ is used to express a sufficiency condition (Goertz and Mahoney 2012).

$$
\text { (4) } \mathrm{I}+\mathrm{P} \rightarrow \mathrm{D}
$$

Scholars of the second school argue that high debt accumulation (D) occurs when there is an adverse economic shock (S) and a coalition government (C) in power that cannot easily close the budget deficit, as shown in Proposition 5.

$$
\text { (5) } \mathrm{S} * \mathrm{C} \rightarrow \mathrm{D}
$$

Proposition 4 states that instability OR polarization is sufficient for high debt accumulation. Proposition 5 states that a shock AND a coalition government is sufficient for high debt accumulation. Table 6 demonstrates the difference between AND and OR using three hypothetical countries:

\section{[TABLE 6 ABOUT HERE]}

In Table 6, Alpha, Beta and Gamma all have membership of the solution formula I+P because they have membership in either I (Alpha) or P (Gamma) or both (Beta). The membership of I+P is equal to the maximum of the memberships of I and P columns. By contrast only Beta has membership of the solution formula $\mathrm{S}^{*} \mathrm{C}$, even though both Alpha and Gamma have membership of $\mathrm{S}$, because a case's membership in $\mathrm{S}^{*} \mathrm{C}$ is equal to the minimum of the memberships of the $\mathrm{S}$ and $\mathrm{C}$ columns. The same procedure can be demonstrated with fuzzy set data, as shown in Table 7:

[TABLE 7 ABOUT HERE] 
Just as in Table 6, the application of the Boolean OR using the solution formula I+P involves the maximum value of the component parts 'I' and 'P', so although Gamma has full non-membership of ' $\mathrm{I}$ ', its full membership of ' $\mathrm{P}$ ' ensures that its membership of ' $\mathrm{I}+\mathrm{P}$ ' is 1.0. The application of the Boolean AND using solution formula $\mathrm{S}^{*} \mathrm{C}$ involves the minimum value of the component parts ' $\mathrm{S}$ ' and ' $\mathrm{C}$ ', so Alpha has just 0.1 membership in $\mathrm{S}^{*} \mathrm{C}$ because it has 0.1 membership in $\mathrm{C}$, despite its full membership of S.

Just as QCA takes a middle-path between statistical quantitative strategies and qualitative case-studies, the exclusive disjunction XOR takes a middle-path between the strict AND and the loose OR. The conjunction of two conditions (AND) is true in only one of the four truth table rows displayed in Table 1. The inclusive disjunction of two conditions (OR) is true in three of the four truth table rows displayed in Table 2. The exclusive disjunction of two conditions (XOR), by contrast, is true in half of the truth table rows (Table 3, rows 2 and 3) and false in the other half (Table 3, rows 1 and 4). The exclusive disjunction is true when either one of its components is true,

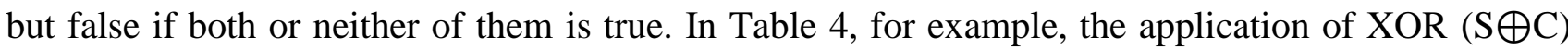
would yield the precise opposite result to $\mathrm{S}^{*} \mathrm{C}$ in column seven: Alpha and Gamma have membership of $\mathrm{S} \oplus \mathrm{C}$ while Beta does not, because Beta has membership of both $\mathrm{S}$ and $\mathrm{C}$. The application of $\mathrm{XOR}(\mathrm{I} \oplus \mathrm{P})$ would yield a slightly stricter result than $\mathrm{I}+\mathrm{P}$ in column six: whereas all three hypothetical countries have membership of $\mathrm{I}+\mathrm{P}$, only two of them have membership of $\mathrm{I} \oplus \mathrm{P}$. Hence $\oplus$ is stricter than + but laxer than $*$. With the fuzzy set scores, displayed in Table 5 , the use of XOR is slightly different and I will discuss this more fully in the final part of this paper.

The inverse of XOR is XNOR, an operator known as the logical or material biconditional in propositional calculus and the 'exclusive nor' in Boolean algebra. The truth table for XNOR is the precise opposite of the XOR truth table: rows 1 and 4 are true while rows 2 and 3 are false. XNOR is true just in case the truth value of the two elements is the same - either both or neither are true - and 
false where just one or the other is true. Like the XOR, XNOR could have applications beyond the fields of logic, mathematics and engineering. For example: objections to the executive line-item veto and to 'selective conscientious objectors' (citizens who refuse to fight in certain wars but not all wars) have a XNOR-like structure. Both full veto and no veto by the President or Governor are acceptable outcomes, but line-item opponents argue that vetoing some but not all of a particular bill empowers the executive too much (Carter and Schap 1990). Similarly, laws regarding conscientious objection have not favoured selectivity. The Draft Act of 1917, for example, exempted only those who refused to fight 'in war in any form', and did not cover American citizens of Austrian or German descent who objected to fighting in the First World War but not to other wars (Greenawalt 1971).

The inversion of XOR (one but not both) to make XNOR (all or neither) underlines the importance of ascertaining why a particular disjunction is exclusive - a topic broached in my introductory section - because both operators assert a relationship between conditions that is either constitutive or causal. Neither rests on simple coincidence. XNOR is known by logicians as the logical biconditional, represented by the double arrow $(\leftrightarrow)$ and formalized as 'if P then Q and if Q then $\mathrm{P}^{\prime}(\mathrm{P}$ iff $\mathrm{Q})$. This is an assertion of a relationship between two states of affairs (and not merely a relationship between two sentences) such that the truth of $\mathrm{P}$ depends upon the truth of $\mathrm{Q}$ and vice versa. XNOR relations in the previous paragraph can be rationalized on the basis of prevailing beliefs about overweening executives and the fairness of wartime rules of conscientious objection. Similarly, XOR asserts a relationship between two states of affairs: that a barrier - either logical or practical - exists between two conditions such that it is not possible to have both together and still produce the outcome of interest. A disjunction is not truly exclusive unless there is a reason why two causal conditions cannot occur together. XOR does not describe situations in which the two conditions merely happen not to coincide in observed cases. 
Using XOR, scholars can improve QCA's claim to understand causal complexity and especially equifinality. XOR asserts a relationship between causal conditions: that one or other produces a certain outcome but both together do not - because they cannot logically occur together, or together they violate a commitment or constraint, or together overshoot the outcome of interest. Instead of leaving the relationship between different causal pathways ambiguous, as with the inclusive disjunction, XOR asserts that something prevents two causal conditions from working together to produce an outcome even though either on its own would produce that outcome.

\section{OR or XOR? Four Examples of OR/XOR Confusion}

It is possible to express XOR in terms of AND, OR and NOT:

\section{$\mathrm{P} X O R \mathrm{Q}=(\mathrm{P}$ OR Q $)$ AND NOT $(\mathrm{P}$ AND Q $)$}

In symbols: $\mathrm{P} \oplus \mathrm{Q}=(\mathrm{P}+\mathrm{Q}) * \neg(\mathrm{P} * \mathrm{Q})$

However, there are several disadvantages in using,$+{ }^{*}$ and $\neg$ rather than the $\bigoplus$ operator explicitly. First, the long-form expression is unwieldy. Secondly, social scientists sometimes use the + operator when they really mean $\oplus$, with the resultant loss of meaning. Thirdly, such scholars fail to enjoy the many advantages of explicit use of $\bigoplus$. This section focuses on the second of these three points: instances of confusion between OR and XOR. Sections three, four and five turn to positive applications of XOR.

Fudging the distinction between OR and XOR leads to ambiguity and a lack of logical clarity. When Aus described the 'seemingly erroneous Boolean expression' $1+1=1$ as the formalization of the phrase 'outcome Y is triggered by the presence of mechanism A or mechanism B' (Aus 2009, 179), he seems to be using the 'or' as an exclusive disjunction, which would imply that $1+1=1$ is 
true only if the + is replaced with $\bigoplus$. Even Ragin implied that the inclusive-or is exclusive when he said of the Boolean OR: 'Satisfy any one of the additive conditions and the expected outcome follows' (Ragin 1987, 89) [my italics].

Some users of QCA express solutions in terms of OR when they really mean XOR. For example, Pennings uses fuzzy set analysis to examine social expenditures and welfare cut-backs in European nations (Pennings 2005). One of his findings is that there are two paths to lower-thanexpected social expenditure cut-backs: 1) countries such as Finland or Italy that lagged behind in the 1980s and increased their expenditures in the 1990s to catch up and 2) countries such as Norway and Sweden where political-institutional factors explain why they maintained relatively high levels of social expenditures. Either of these clusters of conditions characterizes countries that do not cut back as much expenditure as expected (they are each sufficient for the low cut-backs outcome) but the two clusters are mutually incompatible. It is not possible to be both an early-lagger and a continuousleader in expenditures.

The difference between OR and XOR and the value of using XOR explicitly are well illustrated by Varone et al.'s examination of the regulation of assisted reproductive technology (ART) by eleven European and North American countries (Varone, Rothmayr, and Montpetit 2006). The outcome condition in this study is categorized by degree of ART regulation - restrictive, intermediate and permissive - and the five causal conditions are mostly formulated (although the researchers do not explicitly acknowledge it) as a series of exclusive disjunctions: (1) 'Party politics: fragmentation or congruence of beliefs and interests?' (2) 'Physicians and medical researchers: selfregulation of the target groups?' (3) 'Mobilization of interest groups: Policy with or without publics?' (4) 'Number of arenas: Divided powers or unitary state?' and (5) 'Nature of decisionmaking rules: Power sharing or majority?' The causal conditions are abbreviated as follows: fragmentation of party politics $(\mathrm{G})$, polarization in the medical community (M), no or little mobilization by interest groups (I), many arenas (A) and tight power-sharing rules (R). Their 
opposites are symbolized by lower-case letters. They are formulated as INUS conditions, Mackie's term for 'insufficient but necessary parts of a condition that is unnecessary but sufficient for the outcome’' (Mackie 1965).

There are several points at which the inclusive-or is used when the exclusive would be more appropriate. The authors do not actually formulate a single Boolean expression for each regulation type outcome, and if they did so, for two of the paths they should use the XOR rather than OR. For example, the proper formulation of Varone et al.'s two paths to restrictive policies is:

$$
\text { gmRIa } \oplus \text { gmRiA } \rightarrow \text { Restrictive policies }
$$

The two paths to restrictive policies are those taken by Norway (which had no mobilization of interest groups and few arenas) and Germany and Switzerland (which had, on the contrary, both mobilization and many arenas). Since they contradict one another, the paths should not be joined by an inclusive-OR when formulating a single Boolean expression by outcome type. By contrast the authors could use the OR, not the XOR, to join their pathways to permissive policies because the pathways are not mutually exclusive:

$$
\text { GMIR + GMIA } \rightarrow \text { Permissive policies }{ }^{3}
$$

A second reason to use the exclusive-OR in Varone et al.'s study is the fact that a distinctive intermediate outcome condition is identified, covering France, Spain, the UK and the Netherlands. The authors state that they have identified 'a majority of uppercase conditions for the permissive outcomes and of lowercase conditions for restrictive policy design' while the intermediate outcomes are associated with a mix of upper- and lower-case conditions (Varone, Rothmayr, and Montpetit

\footnotetext{
${ }^{3}$ The pathway to intermediate policies would, like the paths to restrictive policies, also require the XOR as follows: gIar $\oplus$ gImAR $\rightarrow$ Intermediate policies.
} 
2006, 338). Such a feature suggests it is possible to both 'overshoot' and 'undershoot'. Whenever all or almost all of the causal conditions are present, the restrictive regime is the outcome. When the causal conditions are absent, the permissive regime is the outcome. When just one (or some other sub-set) of the causal conditions are present, the intermediate regime is the outcome. Any theory of this structure requires the use of the exclusive disjunction because it has the form 'A or B but not both'. Indeed, an intermediate regulatory outcome might seem the most desirable of the three outcomes identified, so the exclusive disjunction is helpful to scholars interested in the conditions that encourage such an intermediate outcome. Section four on XOR applications in social science demonstrates the fruitfulness of using XOR when targeting intermediate outcomes including, for example, anocracy, mixed private-public sector policies or majoritarian-proportional electoral systems.

A third example of OR/XOR ambiguity is found in Kitchener et al.'s article, which used QCA to investigate the causal conditions leading to certain US states' low per-capita spending on home and community-based services (HCBS) waivers (Kitchener, Beynon, and Harrington 2002). The authors found three paths to low HCBS spending, all of which include Republican governors, stringent Medicare eligibility standards and weak HCBS advocacy groups: (1) high numbers of nursing home beds and a strong industry lobby OR (2) strong state finances and a strong industry lobby, OR (3) low numbers of nursing home beds, a weak industry lobby and a state budget deficit. The problem with their use of the Boolean OR is that there are a number of incompatibilities between various elements of the three paths to the outcome. For example, since the authors define the strength or weakness of the consumer lobby relative to the opposing lobby, there is a fundamental incompatibility between paths that display a strong industry lobby and paths that display a strong consumer lobby. Cases should have one or the other but not both. Moreover, each of the three INUS paths contains conditions that have their opposites in other paths: high or low numbers of nursing home beds, for example, or a weak or strong industry lobby. The pathways to 
low HCBS spending that Kitchener et al. expressed in terms of the OR should have been expressed using XOR. As currently formulated, their Boolean expression is ambiguous.

Where exclusive disjunctions arise from logical incompatibility, it might be supposed that the exclusivity of the disjunct is implicit in the use of the Boolean OR so there is no need to convert the OR to XOR. In everyday conversation utterances give rise to conversational implicatures: meanings that can be worked out from how something was said, rather than simply what was said (Grice 1989). It is usually obvious from contextual clues whether a given utterance of 'or' is exclusive or inclusive, but not always. If it were, the phrase 'but not both' would never be uttered. Even logically incompatible conditions may not seem incompatible if they are framed differently (Keren 2007; Druckman 2004). ${ }^{4}$ In social scientific uses of QCA, incompatibilities between conditions are even easier to overlook because measures can be calibrated in complex indirect ways, for example, Kitchener et al.'s consumer and industry lobbies. Distinguishing between XOR and OR is a way to formalize implicature, and implicature is complex, ubiquitous, and essential to linguistic meaning. This mission fits precisely within the broader QCA project: the use of Boolean logic to express complexity in a formalized fashion.

In my fourth example of OR/XOR confusion, Vis's 2011 article on active labour market policy (ALMP) spending in the European Union, there are signs not only that the author used an inclusive disjunction when she should have used an exclusive one but also that she did not implicitly interpret the disjunction in an exclusive way. In Vis's article, two of the paths to increased governmental ALMP spending are incompatible with one another. One features the absence of corporatism (c) and the presence of a leftist government (L); the other features the presence of corporatism (C) and the absence of a leftist government (l) - i.e. presence of a rightist government. Formally: $\mathrm{cL} \oplus \mathrm{Cl}$. The author does not seem to interpret this disjunction exclusively. She states: 'this improving socio-economic situation is sufficient for activation only when combined with (1)

\footnotetext{
${ }^{4}$ Context also matters. A disjunct that seems obviously exclusive and therefore in no need of XOR formalization may not be so in other contexts. The 'or' in 'male OR pregnant', for example, is clearly exclusive amongst humans but inclusive amongst members of the Syngnathidae family, such as seahorses.
} 
openness; (2) the absence of corporatism and a leftist government, or (3) the presence of corporatism and a rightist government'(Vis 2011, 249). But since 'openness' is present in almost all cases, 'most of the cases with membership in the latter two paths also have membership in the first one'(Vis 2011, 245). Hence the disjunction of routes (1) and (2), and routes (1) and (3) is mostly inclusive. Since these disjunctions are interpreted in an inclusive fashion, Vis's statement of three causal paths wrongly implies that the disjunction between routes (2) and (3) is also inclusive. The disjunction is exclusive and should be formalized as such.

For scholars who mistakenly use the Boolean OR when XOR is the appropriate choice, the resulting expressions do not capture the substantive meaning of the terms of the theory: the exclusivity of alternative paths. This is problematic for QCA because QCA attempts to mirror closely the ordinary language of set relations. XOR is the remedy. It is also a useful tool. The next three sections discuss the applications of the exclusive disjunction in QCA. XOR expresses logical and practical incompatibility between causal paths, and the final section applies XOR to fuzzy set analysis.

\section{Logical incompatibility}

Many scholars using QCA identify elements of the solution formulae that can be excluded to create a simplified formula, notably where there is a direct contradiction between elements of two formulae. To use the earlier high debt accumulation example (where, as before, $\mathrm{D}=$ high debt accumulation, $\mathrm{I}=$ instability, $\mathrm{P}=$ party polarization, and a fourth condition is added: $\mathrm{G}=$ left wing government in power) one possible set of solution formulae would be:

(6) $\mathrm{IPG}+\mathrm{IPg} \rightarrow \mathrm{D}$ 
Statement 6 shows two solution formulae which are each sufficient for the outcome, D: instability (I), polarization $(\mathrm{P})$ and a left-wing government in power $(\mathrm{G})$ or instability (I), polarization $(\mathrm{P})$ without a left-wing government in power $(\mathrm{g})$. The common factors are instability and polarization so the left-wing government condition may be left out of the most parsimonious solution because both its presence and absence are part of INUS conditions that lead to high debt accumulation.

$$
\text { Parsimonious solution (6) IP } \rightarrow \text { D }
$$

If contradictory elements ( $\mathrm{G}$ and $\mathrm{g}$ in example 6) are removed as part of the regular simplification of solution formulae to create more parsimonious solutions, then it may seem that the application of XOR is unnecessary. This view is misguided, on two counts: First, a reason to value configurational analysis is that it does not place as much emphasis as correlational analysis does on parsimony. Indeed, part of the attraction of QCA to many social scientists is its holistic approach to cases and acceptance of multiple, conjunctural causation. Rihoux argues that parsimony should not be pursued at all costs in QCA (Rihoux 2006) and Ragin, Rihoux and others have noted that it is desirable to report not only the most parsimonious solution but also the least parsimonious and intermediate solutions (Rihoux and Ragin 2009). The problem when using the Boolean OR to express less parsimonious solutions with logically incompatible conglomerations of conditions is that the solution thus expressed is ambiguous.

The importance of this first point is highlighted by debates about the use of logical remainders and contradictory simplifying assumptions (CSAs) in Boolean minimization of a truth table. Logical remainders are the rows in the truth table that have no real-life cases in them. They are counterfactuals (Goertz and Levy 2007). The remainders are used by QCA software programmes to create solution formulae of differing levels of parsimony. Many scholars have criticized the use of 'non-plausible' logical remainders that could not possibly exist in reality (Romme 1995, 325-6). 
Even Rihoux and Ragin, who defend the unrestricted use of logical remainders in their configurational methods book, state that 'in most situations, we do not advocate this practice' (Rihoux and Ragin 2009, 51:152). Using CSAs, that is, exploiting the same logical remainders both for the minimization of configurations with outcome [1] and the minimization of configurations with outcome [0], is likewise defended by Ragin and Rihoux but their language betrays a deep unease: 'Gladly, in this example, it [CSA] is not the case' [my italics]. They are right to be uneasy; such methods require scholars to posit a logically impossible scenario as a condition for a target outcome. Similarly, using XOR instead of OR when dealing with logically incompatible equifinal solution formulae brings logical clarity and avoids ambiguity or falsehood.

The second reason to resist the 'XOR is unnecessary' charge is that, as the opening part of this paper made clear, there are many more ways to use the exclusive rather than the inclusive disjunction than mere logical incompatibility. The two conditions joined by $\bigoplus$ may produce full non-membership in the outcome variable not because they cannot logically exist at the same time but because they violate a prior commitment or together overshoot the outcome of interest: practical incompatibility.

\section{Practical incompatibility: XOR Applications}

To illustrate the applications of XOR in social science, consider the following hypothetical story, loosely based around existing theories. In the characteristic language of configurational analysis, but long before the development of QCA as a methodology in political science, Barrington Moore listed five pre-conditions that are required for the development of Western-style democracy (D) (Moore 1967): 
1. The 'development of a balance to avoid too strong a crown or too independent a landed aristocracy’ (B)

2. A shift toward 'an appropriate form of commercial agriculture' (A)

3. A weakening of 'the landed aristocracy' (L)

4. The prevention of 'an aristocratic-bourgeois coalition against the peasants and workers' (C)

5. A 'revolutionary break with the past'. (P)

Although Moore himself does not describe it in such terms, in his work the five conditions together comprise a necessary condition (expressed using the backward arrow $\leftarrow$ ) for Western-style democracy. Moore's conditions can be expressed in Boolean form as follows:

\section{$\mathrm{BAlcP} \leftarrow \mathrm{D}$}

More recently, scholars of democratization have not only challenged Moore's structural preconditions but also introduced more sophisticated treatments of the outcome. 'Democracy' is no longer treated as a monolithic category and a range of non-democratic and intermediate outcomes have been identified. One such intermediate outcome is 'anocracy', 'a regime that mixes democratic with autocratic features' (Edwards 1994). In anocracies, which can be identified by their mid-range scores on the POLITY index, nominally democratic institutions (legislatures, elections and parties) coexist with dictatorship, because the ruling dictators need to offer policy concessions in return for the support of social groups outside of the ruling elite. Scholars of democratization study the conditions under which successful democratic transition is possible (as Moore did) but also the conditions under which democratization is either completely reversed or else 'stalled' in the anocracy camp (Tilly 2003; Sweet 2001; Fish and Wittenberg 2009). The study of such mid-range values might require the use of the exclusive disjunction, as I describe below. 
A scholar might argue that democracy (D) is produced when all five of Moore's preconditions are in place (switching the arrow to a sufficiency condition ' $\rightarrow$ ' for ease of interpretation). Where none of the pre-conditions are in place the outcome is dictatorship (T). However, where just one (or some other sub-set) of the conditions is in place then the outcome will be the mid-range result, anocracy $(\mathrm{N})$. Two possible theories might state:

$$
\begin{gathered}
\text { (11) } \mathrm{b} \oplus \mathrm{a} \oplus \mathrm{L} \oplus \mathrm{C} \oplus \mathrm{p} \rightarrow \mathrm{N} \\
(12) \mathrm{BA} \oplus \mathrm{lcP} \rightarrow \mathrm{N}
\end{gathered}
$$

(11) states that a lack of balance between crown and aristocracy XOR no commercial agriculture XOR a strong landed aristocracy XOR an aristocratic-bourgeois coalition against the peasants and workers XOR no revolutionary break with the past, are sufficient for anocracy. If more than one of these conditions is in place then dictatorship (T), not anocracy $(\mathrm{N})$ would be the outcome. If on the other hand the scholar were examining the relationship between anocracy and democracy, then he or she might formulate (12). Proposition 12 states that a balance between crown and aristocracy and commercial agriculture XOR a weakened landed aristocracy, the absence of an aristocratic bourgeois coalition and a revolutionary break with the past is sufficient for anocracy. If both of these conditions (BA and lcP) were in place then democracy (D), not anocracy (N) would be the outcome. The theory encapsulated by Proposition 11 displays the conditions under which polities might 'undershoot' anocracy and end up back in dictatorship, while the theory encapsulated by Proposition 12 displays the conditions under which polities might 'overshoot' anocracy and democratize fully. A glossary of these terms is available in the appendix.

This story involves a balancing act. For scholars studying anocracy, the target outcome is the mid-range mixture of democracy and dictatorship. In this case the conditions that produce democracy should be reformulated in terms of XOR, not OR or AND. The anocracy outcome cannot reliably be 
produced by AND or OR. By hypothesis, the application of the AND to Moore's conditions would always produce full democracy while the application of the OR could produce either anocracy or full democracy. To guarantee the mid-range variable, and express a sufficiency relation between the presence or absence of the causal conditions and the target outcome, the XOR must be deployed.

\section{Using XOR in fuzzy set analysis}

The application of XOR to the crisp sets in Table 4 is relatively simple because it follows two simple rules:

XOR Rule 1: If the two values of conditions $\mathrm{P}$ and $\mathrm{Q}$ are different, the $\mathrm{P} \oplus \mathrm{Q}$ value is 1

XOR Rule 2: If the two values of conditions $\mathrm{P}$ and $\mathrm{Q}$ are the same, the $\mathrm{P} \oplus \mathrm{Q}$ value is 0

These two simple XOR rules are similar to the rules for AND and OR

AND Rule 1: If the minimum of the $\mathrm{P}$ and $\mathrm{Q}$ values is 1 , the $\mathrm{P}^{*} \mathrm{Q}$ value is 1 AND Rule 2: If the minimum of the $\mathrm{P}$ and $\mathrm{Q}$ values is 0 , the $\mathrm{P}^{*} \mathrm{Q}$ value is 0

OR Rule 1: If the maximum of the $\mathrm{P}$ and $\mathrm{Q}$ values is 1 , the $\mathrm{P}+\mathrm{Q}$ value is 1 OR Rule 2: If the maximum of the $\mathrm{P}$ and $\mathrm{Q}$ values is 0 , the $\mathrm{P}+\mathrm{Q}$ value is 0

The rules for AND and OR ('take the minimum', 'take the maximum') can be transplanted to fuzzy set analysis easily but this route is harder for XOR. An obvious way to apply XOR to fuzzy sets would be to have the $\mathrm{P} \oplus \mathrm{Q}$ value take the higher of the two fuzzy set values (as with $\mathrm{OR}$ ) except where the values of $\mathrm{P}$ and $\mathrm{Q}$ are precisely the same, whereupon the value of $\mathrm{P} \oplus \mathrm{Q}$ would be 0 . But 
this method cannot do because fuzzy set scores are unlikely to be precisely the same for both conditions, especially where there are a large number of qualitative breakpoints or the fuzzy sets are continuous. Moreover, such a procedure would not capture the intuitive understanding of the exclusive disjunction as incorporating situations where there are (1) prior commitments on the causal configuration side, (2) intermediate outcome solutions that can easily be overshot, and (3) logically incompatible configurations. To see this, consider the following table of five hypothetical set memberships in two causal conditions and the application of the exclusive disjunction to these two conditions, Table 8:

\section{[TABLE 8 ABOUT HERE]}

The first two fuzzy set cases in Table 8, Delta and Epsilon, can be classified using the exclusive disjunction quite easily. Delta has full set membership of both $\mathrm{P}$ and $\mathrm{Q}$, so it has full nonmembership of $\mathrm{P} \oplus \mathrm{Q}$ according to XOR Rule 2. Epsilon has almost full membership of Q and full non-membership of $\mathrm{P}$, so it can be classified in a similar fashion to the procedure for crisp-sets by XOR Rule 1. Like $\mathrm{P}+\mathrm{Q}, \mathrm{P} \oplus \mathrm{Q}$ takes the value of the higher of the two component parts when the other component part is full non-membership.

The problem arises with the remaining three cases: Zeta, which is almost completely in $\mathrm{P}$ set but almost (and not totally) out of Q set; Eta, which is more out that in P set (set membership 0.4) but more in than out of Q set (set membership 0.6); and Theta, which has identical set membership scores in $\mathrm{P}$ and $\mathrm{Q}(0.4)$. If the XOR procedure for crisp sets were applied mechanically to the data in Table 8, then Zeta's membership in P $\oplus \mathrm{Q}$ would be 0.9, Eta's 0.6 and Theta's 0.0. But these values do not easily capture the three substantive uses of XOR outlined above: pre-commitments, overkill and logical impossibility. If $\mathrm{P}$ and $\mathrm{Q}$ were truly logically incompatible, then the values in Delta and Theta cases should not occur. If they did, they would lead the researcher to reconsider his or her coding and operationalization of the causal conditions. If the incompatibility were not logical but 
practical, however, such as when the two solution formulae together violate a pre-commitment ('avoid creative accounting') or overshoot a target outcome ('hit the universities admissions band'), then it is perfectly possible to find cases with similar set memberships in both $\mathrm{P}$ and $\mathrm{Q}$.

In crisp-set analysis XOR requires that where the values of $\mathrm{P}$ and $\mathrm{Q}$ are the same the membership of $\mathrm{P} \oplus \mathrm{Q}$ is 0 . This makes sense when full membership of the 'attracting students with good performance' and 'attracting students with aggressive marketing' sets together prevents the university from hitting the admissions band (overkill), or full membership of the 'tight debt rules' and 'tight revenue rules' sets violates a prior commitment (avoid creative accounting). The problem is that Theta's memberships of both P and Q are a modest 0.4 (according to Ragin they are 'more out than in'(Ragin 2008) the P set). Moreover, Theta has the same set-membership of P and only slightly less set-membership of Q than Eta which, according to the mechanical application of XOR, would score 0.6. It makes no sense substantively to require by XOR application that wherever the values of the two solution formulae are the same, no matter how small they are, the value of the PÐQ set should be zero. Similarly, it makes no sense substantively to treat Eta with the leniency of the OR while treating Theta with extreme strictness. If the analysis used a continuous fuzzy set and Theta values were 0.399 and 0.4001 in $\mathrm{P}$ and $\mathrm{Q}$ respectively then, according to this application of XOR, $\mathrm{P} \oplus \mathrm{Q}$ would score 0.4001 . If the exclusive disjunction is to be useful in social science then a slight increase in the fuzziness of the set-membership measurement should not result in such a large leap in a case's membership in the exclusive disjunction of the two values.

The XOR can be applied to fuzzy sets by breaking down the XOR into its component parts: AND, OR and NOT, and finding the value of $(\mathrm{P}+\mathrm{Q})^{*} \mathrm{NOT}-\left(\mathrm{P}^{*} \mathrm{Q}\right)$. It is possible to apply the exclusive disjunction to fuzzy set values using several intermediate steps. Table 9 shows this process:

[TABLE 9 ABOUT HERE] 
Since $\mathrm{P} \oplus \mathrm{Q}=(\mathrm{P}+\mathrm{Q})^{*} \mathrm{NOT}\left(\mathrm{P}^{*} \mathrm{Q}\right)$, taking the inverse of the value for $\mathrm{P}^{*} \mathrm{Q}$ as an intermediate step (column 5), it is possible to calculate the fuzzy set value of $P \oplus Q$. The values in column 6 chime with our intuitive understanding of exclusivity issues: Whereas Delta's full membership of both P and $\mathrm{Q}$ guarantee it full non-membership of $\mathrm{P} \oplus \mathrm{Q}$, Theta's status as 'more out than in' the sets of $\mathrm{P}$ and $\mathrm{Q}$ gives it a similar status in the set of $\mathrm{P} \oplus \mathrm{Q}-0.4$, not 0.0 . Even though membership of both $\mathrm{P}$ and Q 'overshoots' the outcome of interest, low-to-moderate membership of both P and Q does not. Hence Delta 'overshoots' and has full non-membership of $\mathrm{P} \oplus \mathrm{Q}$, while Theta does not overshoot and has partial membership of $\mathrm{P} \oplus \mathrm{Q}$. Both Epsilon and Zeta have 0.8 membership of $\mathrm{P} \oplus \mathrm{Q}$, since Epsilon has full non-membership of P and Zeta is almost (but not completely) out of set Q. Note that this process of applying XOR to fuzzy sets is logically equivalent to:

$$
\min (\max (P, Q), \max (p, q))
$$

In other words, the exclusive disjunction of two fuzzy sets: $\mathrm{P}$ and $\mathrm{Q}$, is equal to the minimum of the value of $\mathrm{P}$ or $\mathrm{Q}$, whichever is higher, and the value of $\mathrm{p}$ or $\mathrm{q}$, whichever is higher.

This operation of XOR to fuzzy sets has the advantages of being relatively swift, clear, and requiring no further knowledge on the part of the researcher, but it treats overkill or pre-commitment violation crudely. Wherever either the value of $\mathrm{P}+\mathrm{Q}$ is lower or $\mathrm{P}^{*} \mathrm{Q}$ is higher than the point of maximum ambiguity (0.5), or both, then the value of $\mathrm{P} \oplus \mathrm{Q}$ will be lower than the point of maximum ambiguity (more out of the set than in). Vice versa where $\mathrm{P}+\mathrm{Q}$ is higher or $\mathrm{P}^{*} \mathrm{Q}$ lower than 0.5 . This application has no means of conveying just how precarious the balance is, when the presence of two conditions makes it easy to overshoot a target outcome. For some exclusive disjunctions, even low levels of set membership might violate the rule 'but not both', while for others, only full membership of both sets will do so. It is possible to calibrate the application of XOR to fuzzy sets in order to identify the precise point at which exclusivity starts to bite, but I elucidate this procedure elsewhere. It is beyond the scope of this paper. 


\section{Conclusion}

Applying Boolean XOR to QCA provides social science researchers with a valuable new tool for expressing mutually exclusive clusters of sufficiency conditions. As this paper has shown, the exclusive disjunction is commonly employed in academic research in the social sciences but such clusters currently lack effective logical expression. Some users of QCA have inadvertently created ambiguous Boolean expressions, as a matter of logic or from practical considerations, because they employ the Boolean OR when they should really use XOR. The utilization of the Boolean XOR exemplifies many of the features that make QCA attractive to researchers: careful calibration, elucidation of conglomerations of causal conditions, and the junking of the additivity assumption of conventional statistical research.

Since, as Ragin points out, most social science theory is verbal, and verbal theory is largely set-theoretic in nature (Ragin 2006a, 291), QCA captures much of how we typically speak about the world (example set relations include: 'no bourgeois, no democracy', 'all school voucher programmes have been passed under unified Republican government', 'states will adopt a given policy alternative if and only if they have the willingness and opportunity to do so', 'revolution becomes possible when

a condition of multiple dysfunction meets an intransigent elite'). ${ }^{5}$ The use of the XOR enables QCA to mimic natural language with much more precision. Unlike those joined by OR, conditions joined with the XOR cannot simply be added together without affecting the target outcome. Against the '(almost) anything goes' looseness of the OR, the XOR preserves QCA's attention to cases as complex conglomerations of causal conditions that cannot simply be substituted or added to one another regardless. Since politics often involves both compromise and zero-sum decisions that

\footnotetext{
${ }^{5}$ Latter two examples taken from (Goertz 2003)
} 
emphasize the mutual exclusiveness of two alternatives, QCA's lack of attention to the exclusive disjunction is a deficiency in its methodological toolkit. This paper remedies that omission. 


\section{References}

Akers, S.B. 1959. "On a Theory of Boolean Functions.” Journal of the Society for Industrial \& Applied Mathematics 7 (4): 487-498.

Aus, J.P. 2009. "Conjunctural Causation in Comparative Case-Oriented Research." Quality and Quantity 43 (2) (March): 173-183.

Carter, J.R., and D Schap. 1990. "Line-Item Veto: Where Is Thy Sting?" The Journal of Economic Perspectives 4 (2): 103-118.

Druckman, J.N. 2004. "Political Preference Formation: Competition, Deliberation, and the (ir)relevance of Framing Effects.” American Political Science Review 98 (4): 671-686.

Edwards, A. 1994. "Causes of Bewilderment: Necessity, Sufficiency and Facilitating Conditions for Democratization." Democratization 1 (2): 444-460.

Felix, R. 1994. "Relationships between Goals in Multiple Attribute Decision Making." Fuzzy Sets and Systems 67 (1): 47-52.

Ferris, J.M. 1992. "A Contractual Approach to Higher Education Performance: With an Application to Australia." Higher Education 24: 503-516.

Fish, S.M., and J Wittenberg. 2009. "Failed Democratization.” Democratization: 249-65.

Fleisher, H, M Tavel, and J Yeager. 1983. "Exclusive-OR Representations of Boolean Functions." IBM Journal of Research and Development 27 (4): 412-416.

Goertz, G. 2003. “The Substantive Importance of Necessary Condition Hypotheses.” In Necessary Conditions: Theory, Methodology, and Applications, edited by G Goertz and H Starr.

Lanham, MD: Rowman \& Littlefield.

Goertz, G, and J.S. Levy. 2007. Explaining War and Peace: Case Studies and Necessary Condition Counterfactuals. Taylor \& Francis.

Goertz, G, and J Mahoney. 2012. "Methodological Rorschach Tests: Contrasting Interpretations in Qualitative and Quantitative Research.” Comparative Political Studies 46 (2) (February): 236-251.

Greenawalt, K. 1971. "All or Nothing At All: The Defeat of Selective Conscientious Objection." Supreme Court Review 31: 31-94.

Grice, H.P. 1989. Studies in the Way of Words. Cambridge MA: Harvard University Press.

Haan, J.D., and J.E. Sturm. 1994. "Political and Institutional Determinants of Fiscal Policy in the European Community." Public Choice 80: 157-172.

Hodder-Williams, R. 1996. "British Politicians: To Rehabilitate or Not?" Parliamentary Affairs 49 (2): 285-297.

Hurford, J.R. 1974. "Exclusive or Inclusive Disjunction.” Foundations of Language 11 (3) (May): 409-411.

Jennings, G. 1994. The Geneology of Disjunction. New York and Oxford: Oxford University Press.

Keren, G. 2007. "Framing, Intentions, and Trust-Choice Incompatibility." Organizational Behavior and Human Decision Processes 103 (2) (July): 238-255.

Kitchener, M, M Beynon, and C Harrington. 2002. "Qualitative Comparative Analysis and Public Services Research: Lessons from an Early Application.” Public Management Review 4 (4): 485-504.

Mackie, J.L. 1965. "Causes and Conditions.” American Philosophical Quarterly 2 (4) (October): 245-264.

Milesi-Ferretti, G.M. 2004. "Good, Bad or Ugly? On the Effects of Fiscal Rules with Creative Accounting." Journal of Public Economics 88 (1-2) (January): 377-394.

Moore, B. 1967. Social Origins of Dictatorship and Democracy: Lord and Peasant in the Making of the Modern World. Boston: Beacon Press.

Pennings, P. 2005. "The Diversity and Causality of Welfare State Reforms Explored with FuzzySets." Quality and Quantity 39: 317-339. 
Ragin, C.C. 1987. The Comparative Method: Moving Beyond Qualitative and Quantitative Strategies. Berkely, Los Angeles and London: University of California Press. . 2006. "Set Relations in Social Research: Evaluating Their Consistency and Coverage." Political Analysis 14 (3): 291-310.

2008. Redesigning Social Inquiry: Fuzzy Sets and Beyond. Chicago and London: University of Chicago Press.

Rihoux, B. 2006. "Qualitative Comparative Analysis (QCA) and Related Systematic Comparative Methods: Recent Advances and Remaining Challenges for Social Science Research." International Sociology 21 (5) (September): 679-706.

Rihoux, B, and C.C. Ragin, ed. 2009. Configurational Comparative Methods: Qualitative Comparative Analysis (QCA) and Related Techniques. Vol. 51. Applied Social Research Methods Series. Los Angeles: Sage Publishing.

Romme, A.G.L. 1995. "Boolean Comparative Analysis of Qualitative Data." Quality and Quantity 29: 317-329.

Schaechter, A, T Kinda, N Budina, and A Weber. 2012. "Fiscal Rules in Response to the CrisisToward the 'Next-Generation' Rules. A New Dataset." International Monetary Fund Working Paper (July): 1-49.

Schneider, C.Q., and C Wagemann. 2006. "Reducing Complexity in Qualitative Comparative Analysis (QCA): Remote and Proximate Factors and the Consolidation of Democracy." European Journal of Political Research 45 (5) (August): 751-786.

Simpson, J, ed. 2004. "Or, Conj. 2. In Correlative Constructions." Oxford English Dictionary. Oxford: Oxford University Press.

Sweet, C. 2001. "Democratization without Democracy: Political Openings and Closures in Modern Morocco." Middle East Report 218: 22-25.

Taagepera, R. 2008. Making Social Sciences More Scientific: The Need for Predictive Models. New York: Oxford University Press.

Tilly, C. 2003. "Inequality, Democratization, and De-Democratization." Sociological Theory 21 (1): $37-43$.

Varone, F, C Rothmayr, and E Montpetit. 2006. "Regulating Biomedicine in Europe and North America: A Qualitative Comparative Analysis." European Journal of Political Research 45 (2): 317-343.

Vis, B. 2011. "Under What Conditions Does Spending on Active Labor Market Policies Increase? An fsQCA Analysis of 53 Governments between 1985 and 2003." European Political Science Review 3 (2) (July): 229-252.

Wagemann, C, and C.Q. Schneider. 2010. "Qualitative Comparative Analysis (QCA) and FuzzySets: Agenda for a Research Approach and Data Analysis Technique." Comparative Sociology 9 (3): 376-396.

Whitehead, F. 2012. "Student Recruitment Strategy: Four Universities, Five Key Questions". The Guardian Higher Education Network. http://www.guardian.co.uk/higher-educationnetwork/blog/2012/nov/13/student-recruitment-strategy-international-universities. 


\section{Appendix}

\section{Glossary of Terms}

\begin{tabular}{|l|l|}
\hline Term & Definition \\
\hline Exclusive disjunction & A or B, but not both \\
\hline Inclusive disjunction & A or B, or both \\
\hline Logical incompatibility & $\begin{array}{l}\text { Where two conditions cannot logically occur } \\
\text { simultaneously }\end{array}$ \\
\hline Practical incompatibility & $\begin{array}{l}\text { Where two conditions cannot occur simultaneously } \\
\text { because they would together violate a prior commitment } \\
\text { or overshoot the outcome of interest }\end{array}$ \\
\hline Target category & The outcome of interest \\
\hline Intermediate outcome/Mid-range values & $\begin{array}{l}\text { A distinctive outcome condition (dependent variable) that } \\
\text { lies between two other conditions along a particular } \\
\text { dimension, so that its values on that dimension are } \\
\text { between the two extremes. }\end{array}$ \\
\hline Overshoot/ Overkill & $\begin{array}{l}\text { Where the presence of just one of two causal conditions } \\
\text { (independent variables) results in the target intermediate } \\
\text { outcome, but the presence of both causal conditions results } \\
\text { in a value along a particular dimension that is higher than } \\
\text { the target outcome. The target outcome is not reached. }\end{array}$ \\
\hline Undershoot & $\begin{array}{l}\text { Where the presence of precisely one of two causal } \\
\text { conditions (independent variables) results in the target } \\
\text { intermediate outcome, but the presence of neither causal } \\
\text { condition results in a value along a particular dimension } \\
\text { that is lower than the target outcome. The target outcome } \\
\text { is not reached. }\end{array}$ \\
\hline Fuzzy Set XOR application & $\begin{array}{l}\text { Split the exclusive disjunction into its component parts to } \\
\text { find the fuzzy set value of each case according to the } \\
\text { formula: min(max(A,B),max(a,b)) }\end{array}$ \\
\hline
\end{tabular}




\section{But Not Both: The Exclusive Disjunction in Qualitative Comparative Analysis TABLES AND FIGURES}

Table 1: Ten selected publications with exclusive disjunctions in the title

'Comparative Political Communications: Common Frameworks or Babelian Confusion?'

'The Labour Alliance: Reality or Myth?'

'Human trafficking and migration control policy: vicious or virtuous cycle?'

'Public debt and budgetary procedures: top down or bottom up?'

'Religion and Democracy in the United States: Danger or Opportunity?'

'The Lobby System: Lubricant or Spanner?'

'Faith-based Organizations and Welfare State Retrenchment in Sweden: Substitute or Complement?'

'Rubber-Stamp or Cockpit? The Impact of Parliament on Government Legislation'

'Tiebout? or Not Tiebout? The Market Metaphor and America's Devolution Debate'

'British Politicians: To Rehabilitate or Not? ${ }^{6}$

\footnotetext{
${ }^{6}$ C Fridolfsson and I Elander, "Faith-based Organizations and Welfare State Retrenchment in Sweden: Substitute or Complement?," Politics and Religion 5, no. 3 (December 2012): 634-654; L.P. Feld and G Kirchgassner, "Public Debt and Budgetary Procedures: Top down or Bottom up? Some Evidence from Swiss Municipalities," in Fiscal Institutions and Fiscal Performance (Chicago: University of Chicago Press, 1999), 151-180; N Avdan, "Human Trafficking and Migration Control Policy: Vicious or Virtuous Cycle?," Journal of Public Policy 32, no. 3 (December 2012): 171-205; A Wolfe and I Katznelson, Religion and Democracy in the United States: Danger or Opportunity? (Princeton, NJ: Princeton University Press, 2010); P Norris, "Comparative Political Communications: Common Frameworks or Babelian Confusion?," Government and Opposition 44, no. 3 (2009): 321-340; D Farnham, "The Labour Alliance: Reality or Myth?," Parliamentary Affairs XXIX, no. 1 (1976): 37-46; B Ingham, "The Lobby System: Lubricant or Spanner?," Parliamentary Affairs 47, no. 4 (1994): 549-565; S Kalitowski, "Rubber Stamp or Cockpit? The Impact of Parliament on Government Legislation," Parliamentary Affairs 61, no. 4 (2008): 694-708; R Hodder-Williams, "British Politicians: To Rehabilitate or Not?," Parliamentary Affairs 49, no. 2 (1996): 285-297.
} 
Table 2: Five selected publications with explicit inclusive disjunctions in the title

'Instrumental calculation, cognitive role-playing, or both? Self-perceptions of seconded national experts in the European Commission'

'Public Management: Should It Strive to be Art, Science, or Engineering?'

'Contradictory Demands on the First Amendment Religion Clauses: Having it Both Ways'

'Blacks, Whites, or Grays? Conditional Transfers and Gender Equality in Latin America'

'Regulation by Prices, Quantities, or Both: A Review of Instrument Choice'7

\footnotetext{
${ }^{7}$ Z Murdoch and B Geys, "Instrumental Calculation, Cognitive Role-playing, or Both? Self-perceptions of Seconded National Experts in the European Commission," Journal of European Public Policy 19, no. 9 (2012): 1357-1376; B.N. Evans, "Contradictory Demands on the First Amendment Religion Clauses: Having It Both Ways," Journal of Church and State 30, no. 3 (1988): 463-491; R Behn, "Public Management: Should It Strive to Be Art, Science, or Engineering?," Journal of Public Administration Research and Theory 6, no. 1 (1996): 91-123; J.M. Franzoni and K Voorend, "Blacks, Whites, or Grays? Conditional Transfers and Gender Equality in Latin America," Social Politics 19, no. 3 (Fall 2012): 383-407; C Hepburn, "Regulation by Prices, Quantities, or Both: A Review of Instrument Choice," Oxford Review of Economic Policy 22, no. 2 (Summer): 226-247.
} 
Table 3: 'AND'

\begin{tabular}{ccc}
\hline $\mathbf{A}$ & $\mathbf{B}$ & $\mathbf{A} * \mathbf{B}$ \\
\hline 1 & 1 & 1 \\
1 & 0 & 0 \\
0 & 1 & 0 \\
0 & 0 & 0
\end{tabular}


Table 4: 'OR'

\begin{tabular}{ccc}
\hline $\mathbf{A}$ & $\mathbf{B}$ & $\mathbf{A + B}$ \\
\hline 1 & 1 & 1 \\
1 & 0 & 1 \\
0 & 1 & 1 \\
0 & 0 & 0
\end{tabular}


Table 5: 'XOR'

\begin{tabular}{ccc}
\hline $\mathbf{A}$ & $\mathbf{B}$ & $\mathbf{A} \bigoplus \mathbf{B}$ \\
\hline 1 & 1 & 0 \\
1 & 0 & 1 \\
0 & 1 & 1 \\
0 & 0 & 0
\end{tabular}


Figure 1: 'AND'

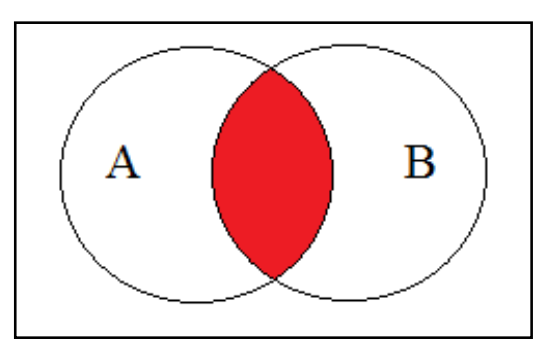


Figure 2: ' $O R$ '

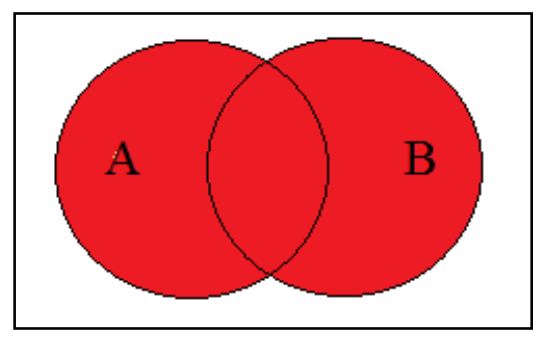


Figure 3: 'XOR'

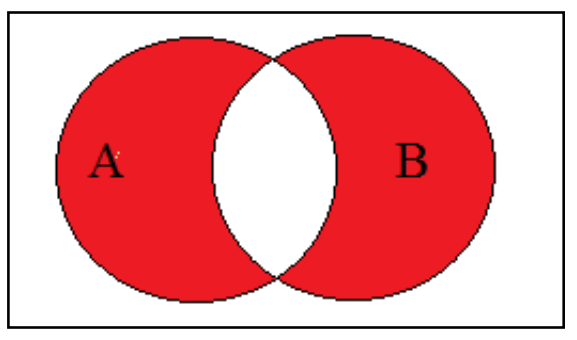


Table 6: Hypothetical crisp-set membership in the four conditions

\begin{tabular}{ccccccc}
\hline Country & $\mathbf{I}$ & $\mathbf{P}$ & $\mathbf{S}$ & $\mathbf{C}$ & $\mathbf{I}+\mathbf{P}$ & $\mathbf{S} * \mathbf{C}$ \\
\hline Alpha & 1 & 0 & 1 & 0 & 1 & 0 \\
Beta & 1 & 1 & 1 & 1 & 1 & 1 \\
Gamma & 0 & 1 & 1 & 0 & 1 & 0
\end{tabular}


Table 7: Hypothetical fuzzy-set membership in the four conditions

\begin{tabular}{ccccccc}
\hline Country & $\mathbf{I}$ & $\mathbf{P}$ & $\mathbf{S}$ & $\mathbf{C}$ & $\mathbf{I}+\mathbf{P}$ & $\mathbf{S} * \mathbf{C}$ \\
\hline Alpha & 0.8 & 0.2 & 1.0 & 0.1 & 0.8 & 0.1 \\
Beta & 0.7 & 0.7 & 0.9 & 1.0 & 0.7 & 0.9 \\
Gamma & 0.0 & 1.0 & 0.5 & 0.6 & 1.0 & 0.5
\end{tabular}


Table 8: Hypothetical fuzzy set membership and

XOR application for social science

\begin{tabular}{cccc}
\hline Case & $\mathbf{P}$ & $\mathbf{Q}$ & $\mathbf{P} \oplus \mathbf{Q}$ \\
\hline Delta & 1.0 & 1.0 & 0.0 \\
Epsilon & 0.0 & 0.8 & 0.8 \\
Zeta & 0.9 & 0.2 & $0.9 ?$ \\
Eta & 0.4 & 0.6 & $0.6 ?$ \\
Theta & 0.4 & 0.4 & $0.0 ?$
\end{tabular}


Table 9: XOR application for social science, using hypothetical fuzzy set memberships

\begin{tabular}{ccccccc}
\hline Case & $\mathbf{P}$ & $\mathbf{Q}$ & $\mathbf{P + Q}$ & $\mathbf{P} * \mathbf{Q}$ & $\mathbf{N O T}(\mathbf{P} * \mathbf{Q})$ & $\mathbf{P} \oplus \mathbf{Q}$ \\
\hline Delta & 1.0 & 1.0 & 1.0 & 1.0 & 0.0 & 0.0 \\
Epsilon & 0.0 & 0.8 & 0.8 & 0.0 & 1.0 & 0.8 \\
Zeta & 0.9 & 0.2 & 0.9 & 0.2 & 0.8 & 0.8 \\
Eta & 0.4 & 0.6 & 0.6 & 0.4 & 0.6 & 0.6 \\
Theta & 0.4 & 0.4 & 0.4 & 0.4 & 0.6 & 0.4
\end{tabular}

